\title{
(DES)CUIDADO DO PACIENTE COMO FONTE DE SOFRIMENTO MORAL DE DOCENTES DE CURSOS TÉCNICOS EM ENFERMAGEM
}

Carla Godinho Duarte1 ${ }^{1}$ Valéria Lerch Lunardi², Rosemary Silva da Silveira², Edson Luiz Devos Barlem², Graziele de Lima Dalmolin ${ }^{3}$

Objetivo: conhecer como as vivências de docentes de cursos técnicos de enfermagem têm contribuido para seu sofrimento moral (SM). Metodologia: pesquisa qualitativa, mediante entrevistas semiestruturadas, com dez enfermeiros docentes de duas instituições de ensino profissionalizantes do extremo sul do Brasil, e análise textual discursiva. Resultados: construíram-se duas categorias: - (Des) cuidado prestado pelo futuro técnico em enfermagem como fonte de SM ao docente - revelando desinteresse e distanciamento do estudante das práticas de cuidado; - Dinâmica organizacional do ambiente de estágio e (des)cuidado do paciente como fonte de SM do docente, relacionada à precariedade de recursos materiais e a condutas inadequadas dos profissionais de enfermagem. Conclusão: tais situações de descompromisso repercutem em vivências de SM. A problematização do cotidiano, pelos docentes, poderia contribuir para o reconhecimento da dimensão moral presente no sofrimento, entendendo-o como SM, fortalecendo-se para o enfrentamento dos problemas e dilemas morais vivenciados na prática educacional.

Descritores: Enfermagem; Ensino; Educação Profissionalizante; Ética em enfermagem.

\section{THE LACK OF CARE FROM THE PATIENT AS REASON OF MORAL SUFFERING OF TEACHER FROM TECHNICAL NURSING COURSE}

Objective: to know how the life experience of technical nursing course teachers has been decisive for their SM. Methodology: quality research, through interview semi-produced with ten nursing teachers from two professionalizing teaching institutions in southern Brazil, and written text analysis. Results: two categories were built: -The care or lack of care from thefuture nursing technician as the cause of SM in the teaches - expressing lack of interest making students not to participate in inappropriate behavior nursing classes; - Organizational dynamic in the trainee environment and the care or lack of care of the patient as the cause of teachers' SM, related to precarious equipment and inappropriate behavior from nursing professionals.Conclusion: these carelessness situations are causes of SM in nursing teachers. It must considered that if the teachers were concerned they could go forward identifying the moral issue found in suffering, understanding it as SM, getting stronger to face the problem and moral dilemma present in educational practice. Descriptors: Nursing; Education; Professionalizing Education; Ethics Nursing

\section{DESCUIDO DEL PACIENTE COMO FUENTE DE SUFRIMIENTO MORAL DE DOCENTES DE CURSOS TÉCNICOS EN ENFERMERIA}

Objetivo: conocer cómo las vivencias de docentes de cursos técnicos de enfermería han contribuido para su SM. Metodologia: pesquisa cualitativa, bajo entrevistas a medio hechas, con diez enfermeros docentes de dos instituciones de enseñanza profesional del extremo sur de Brasil, y análisis textual discursiva.Resultados: dos clases fueran construidas:- Descuido ofrecido por el futuro técnico en enfermería como fuente de SM al docente - corriendo el velo del desinterés y alejamiento del estudiante de las prácticas del cuidado con directivas y procederes inadecuados; - Dinámica organizacional del contexto de la práctica profesionaly descuido del resignado como fuente de SM del docente, relacionada a la precariedad de recursos materiales y a conductas inoportunas de los profesionales de enfermería. Conclusión: estas situaciones de descompromiso repercuten en vivencias de SM. Se considera que si los docentes problematizasen ese diario, podrían progresar para el reconocimiento del ancho moral listo en el sufrimiento, habiendo la comprensión de eso como SM, fortaleciéndose para el enfrentamiento de las dificultades y disyuntivas morales vividos en la práctica educacional. Descriptores: Enfermería; Enseñanza; Educación para profesionalizarse; Ética en Enfermería

1Enfermeira. Mestre em Enfermagem. Instituto Federal de Educação Ciência e Tecnologia do Rio Grande do Sul - Campus Rio Grande, IFRS. carla.duarte@riogrande.ifrs.edu.br

${ }^{2}$ Enfermeira. Doutor em Enfermagem. Universidade Federal do Rio Grande, FURG.

${ }^{3}$ Enfermeira. Doutor em Enfermagem. Universidade Federal de Santa Maria, UFSM. 


\section{INTRODUÇÃO}

A enfermagem fundamenta-se como uma prática voltada ao cuidado do outro, nos mais variados cenários de atuação. Nesse contexto, insere-se o enfermeiro docente e seu compromisso com a formação de futuros profissionais, que precisam conscientizar-se da responsabilidade que assumem ao desenvolverem práticas de cuidado, atuando com comprometimento e profissionalismo ${ }^{(1)}$

A prática docente, em especial do docente de cursos técnico de enfermagem, entretanto, tem sido influenciada por muitos fatores, relacionados a fragilidades da educação básica do estudante, associadas a sua falta de tempo, descompromisso e desinteresse, manifestos em comportamentos e condutas inadequadas, não condizentes com os preceitos e valores profissionais. Destacam-se, também, as condições de trabalho, quanto a sua elevada carga horária, baixa remuneração, não reconhecimento do compromisso e da complexidade das ações do docente de enfermagem que, além de cuidar, assume a responsabilidade de ensinar o cuidado, o que demonstra a pouca valorização e reconhecimento do trabalho docente, entre outras ${ }^{(1-4)}$.

Estudos revelam, ainda inadequações organizacionais nos ambientes das práticas supervisionadas dos estudantes, com negligências, falta de comprometimento profissional, desrespeito aos direitos dos pacientes, fatores reconhecidos como problemas e dilemas morais e fontes não apenas de sofrimento, mas de sofrimento moral (SM) da equipe de enfermagem ${ }^{(5-7)}$.

O SM caracteriza-se como um doloroso desequilibrio psicológico, vivenciado pelas enfermeiras, quando reconhecem a conduta ética adequada a seguir, porém sentem-se impossibilitadas de agir, frente às limitações de outros ou constrangimentos institucionais ${ }^{(8)}$; ou, também, quando há uma incompatibilidade entre o ambiente interno, ou seja, seus valores, percepções e necessidades e as situações impostas pelo ambiente externo(9).

As vivências de SM na enfermagem têm sido bastante presentes, por sua aproximação com situações de cuidado aos pacientes que envolvem dor, sofrimento, angústia e incerteza quanto aos tratamentos e prognósticos, somados aos obstáculos institucionais. Ainda, o SM não está restrito apenas às áreas clínicas, mas também à área acadêmica, afetando a todos envolvidos com a situação clínica dos pacientes $^{(10)}$

Desta forma, buscando compreender as questões que envolvem o trabalho docente em cursos técnicos em enfermagem e o SM, objetiva-se conhecer como as vivências de docentes de cursos técnicos de enfermagem têm contribuído para seu SM.

\section{METODOLOGIA}

Estudo qualitativo, exploratório-descritivo, desenvolvido em duas instituições de ensino profissionalizantes, com formação de técnico em enfermagem, situadas em uma cidade do extremo sul do Brasil: uma instituição pública (A) e outra privada (B)

Os participantes do estudo foram dez enfermeiros docentes, e atuantes nos cursos há pelo menos seis meses, identificados como ED e um número sequencial.

Como técnica de coleta de dados, de setembro a outubro de 2015, a primeira autora realizou entrevistas semiestruturadas, gravadas, nos respectivos locais de trabalho dos participantes, enfocando: percepções, conflitos e dilemas no trabalho docente.

Os dados foram submetidos à Análise Textual Discursiva,compreendendo a desmontagem dos textos, estabelecimento de relações e captação do novo emergente $\mathrm{e}^{(11)}$. Procedeu-se à validação dos dados com seis participantes que demonstraram disponibilidade.

A Resolução no 466/2012 foi respeitada, com aprovação do Comitê de Ética em Pesquisa da Área da Saúde local (CEPAS), sob o parecer número 094/2015.

\section{RESULTADOS}

Construíram-se duas categorias, apresentadas a seguir.

(Des)cuidado prestado pelo futuro técnico de enfermagem como fonte de SM ao docente

Condutas e comportamentos inadequados dos estudantes, não condizentes com o perfil profissional, necessário ao desenvolvimento de práticas de cuidado efetivas e respeitosas aos pacientes, têm se revelado como fonte de angústia e frustração ao docente: Então, tu tens que estar bem mais em cima do aluno, porque eles estão lidando 
com vidas. (...) é um pouco frustrante, pois tu trabalhas o assunto, trabalha na prática e, em determinado momento, a pessoa faz tal procedimento, e tu questionas, e dizem: 'eu não sabia'; 'eu me esqueci.' Claro, a gente fica frustrada, fica triste, com certeza (ED4); O negativo é isso, de tu quereres que o aluno aprenda mais, se sensibilize, que ele se dê conta de que trabalhar com a vida, que se ele fizer um erro ali, acabou, não tem como voltar. Então, essas coisas são frustrantes, de alguns não terem a visão de que vão cuidar de uma vida, e que aquela vida está nas mãos deles (EDIO).

Percebe-se um distanciamento e desvalorização das práticas de cuidado integral ao paciente, que, embora possam parecer repetitivas, atendem a suas necessidades básicas, provocando sofrimento ao docente: $O$ aluno de hoje não é o mesmo de antes, eles fazem corpo mole, querem só punção, acham que é só isso. Quanta riqueza tu descobres em um banho, tem hora melhor para fazer uma avaliação, um exame físico do que na hora do banho? Aí, eles dizem 'exame físico é coisa de médico ou de enfermeiro (ED8).

Tais condutas, aparentemente, contribuem com a formação de profissionais mais distantes do cuidado do paciente, sem valorizar o contato e a interação com o paciente e seus familiares, ferramentas fundamentais para um cuidado humanizado: (...) eles vão ali, verificam os sinais, vão embora, 'bom dia', voltam, 'boa tarde', medicação e vão embora. É bem técnico, vou ali e faço o que tenho que fazer e saio, para não ter mais contato, aquela interação entre paciente e profissional. O próprio aluno comenta em sala de aula que, após um tempo, o pessoal cria essa barreira, não quer ter esse contato com a familia, porque se criar afinidade, vão começar a chamar a toda hora; então, eu crio essa barreira para não me incomodarem (EDIO).

Os docentes percebem com descontentamento que - estudante visualiza sua formação técnica como uma maior possibilidade de emprego na área, sem entusiasmo, sem demonstrar afinidade com a profissão e os valores profissionais, o que é identificado em como realizam os cuidados de enfermagem: (...) as pessoas estão buscando mais a facilidade da inserção no mercado de trabalho do que realmente realizar uma profissão que elas tenham afinidade; não falo por vocação, porque a profissão se aprende, mas tu tens que ter afinidade (ED5).

\section{Dinâmica organizacional do ambiente de estágio e (des)} cuidado do paciente como fonte de SM do docente

Nas atividades práticas, o modo como o ambiente hospitalar está organizado tem também sido fonte de sofrimento aos docentes, especialmente, quanto à sua precariedade: Na prática, é a falta de recursos materiais que está bem complicada; às vezes, tu chegas ali e não tem nada. Por exemplo, como tu vais fazer uma mudança de decúbito? Tu fazes mudança de decúbito, só que, devido à cama, o paciente volta. Às vezes, queres dar um banho, não tem lençóis; então, o que eu não consigo fazer é devido à falta de estrutura física. Tens que fazer uma medicação, e tens que ir em três ou quatro unidades para achar, sendo que é antibiótico que deveria ter ali; é falta de organização (EDI).

A percepção de condutas inadequadas na prestação de cuidados de enfermagem, nos ambientes em que os estágios são realizados, não se configurando como espaços propícios à formação profissional, tem provocado insatisfação e sofrimento aos docentes: Tinha uma senhora acamada, com dor, câncer terminal e o acompanhante vinha pedir a medicação, e a técnica ficava fazendo crochê e falava: 'eu não vou lá, até que eu termine.' Aí, o que tu fazes nessa situação? 'Perguntei: queres que eu vá? Eu posso ir.; 'vai, tá aí a prescrição.' Fomos lá, vimos o que tinha, diluímos a medicação; quando eu voltei, achei que ela ia me agradecer, e tu sabes o que ela falou? 'Amanhã vão querer que eu vá rápido de novo e vocês não tão aqui'. Isso te deixa muito frustrada, muito triste, e é uma instituição de ensino, e o paciente está lá para ser bem tratado; ninguém vai querer ficar no hospital, isso me deixa muito chateada; e está sendo feito na frente do aluno e, às vezes, o aluno acaba repetindo (EDI); Existe uma barreira que o que a gente ensina não é o que eles aprendem na prática, porque eles vêem muitas coisas erradas, (...) a gente diz para calçar a luva, um exemplo simples, e a gente vê profissionais não calçando, (...) indo e vindo sem lavar as mãos, e eles nos questionam: 'porque disso', existem barreiras negativas, $\operatorname{sim}(E D 7)$.

\section{DISCUSSÃO}

Manifestações evidenciadas pelos enfermeiros docentes entrevistados repercutem em vivências de insatisfação e frustração, envolvendo conflitos morais, geradores de SM. Percebe-se um descompasso entre seus valores e a decisão institucional a seguir nos ambientes em que atuam ${ }^{(12)}$.

Em relação ao (des)cuidado do paciente, destacam-se o descompromisso e o distanciamento do estudante das práticas de cuidado com comportamentos inadequados, não condizentes com conhecimento e valores que precisam ser compreendidos e adotados, ao se assumir a responsabilidade de cuidar de outras pessoas. Evidencia-se o sofrimento docente, comprometido com a construção do futuro profissional que, no entanto, não corresponde às práticas educativas propostas, possivelmente não as identificando como relevantes ao seu processo de formação(2).

Nas atividades de estágio prático, as queixas avançam da carência de recursos para a ausência de humanização no atendimento ${ }^{(13)}$, associadas à falta de competência e comprometimento de alguns profissionais e desrespeito aos direitos do paciente $\mathrm{e}^{(6,7)}$.

14 | Enferm. Foco 2016; 7 (2): 12-16 
Ainda, na dimensão de des(cuidado) do paciente, destacam-se condutas inadequadas, quando os estudantes demonstram interesse apenas pelo aprendizado do novo ou adotam uma conduta evasiva frente ao contato com o paciente e seus familiares. Desconsideram, assim, a essência da enfermagem, que está alicerçada no atendimento às necessidades do paciente, independente do seu grau de complexidade ${ }^{(14)}$.

Tais vivências tem se configurado como fontes de frustração para o docente, possivelmente evoluindo para SM, pois vê as situações sendo conduzidas na contramão de suas crenças e valores. $O$ ensino da enfermagem tem predisposto docentes a vivenciarem dilemas morais, pois a eles são atribuídas múltiplas responsabilidades simultaneamente: preparação dos estudantes como profissionais competentes, defesa das normas da profissão e garantia de assistência segura aos pacientes ${ }^{(15)}$

O enfermeiro docente, além de cuidar, assume a responsabilidade de ensinar o cuidado. Esse é um grande desafio, pois requer a consciência que competências técnicas não são suficientes para o desenvolvimento do cuidado, sendo necessária a construção conjunta do conhecimento com vistas à formação ética, empoderamento, empatia e solidariedade no âmbito do fazer, sem perder o entusiasmo para o cuidado(4).

A percepção da falta de entusiasmo e de afinidade de estudantes com os valores profissionais tem sido fonte de sofrimento ao docente. Um estudo com acadêmicos de um curso de graduação em enfermagem revela que a falta de identificação com as atividades da profissão podem estar relacionadas ao pouco conhecimento do curso ou à falta de interesse pela profissão escolhida ${ }^{(16)}$.

A dinâmica organizacional do ambiente de estágio, comprometendo o cuidado do paciente, constitui-se em fonte de sofrimento aos docentes, destacando-se a precariedade dos recursos materiais do ambiente hospitalar, diretamente relacionada à crise de qualidade do atendimento ${ }^{(12)}$.

O docente tem responsabilidade e compromisso, pois a formação envolve a construção do conhecimento, o desenvolvimento de habilidades técnicas e da sensibilidade moral de futuros profissionais, com vistas à assistência e ao cuidado de outras pessoas. As condições de trabalho, entretanto, frente à constatação da precariedade de recursos, sejam materiais, sejam humanos, podem não propiciar o desenvolvimento de práticas da forma adequada, gerando conflitos internos, pois desempenham sua prática docente diferentemente da que gostariam de realizar ${ }^{(2,17)}$. Por vezes, o docente sequer percebe seu sofrimento frente aos conflitos a que a organização do trabalho o submete $e^{(17)}$.

Condutas inadequadas de profissionais de enfermagem, nos ambientes em que os estágios são realizados, representam uma prática assistencial descomprometida técnica e eticamente com o cuidado, contrariando os preceitos da profissão, ratificando que esses espaços podem não se mostrar propícios à formação profissional. Outro estudo também evidenciou que os campos de atividades práticas e de estágios supervisionados nem sempre possibilitam o alcance dos objetivos das disciplinas ${ }^{(18)}$.

Ainda, a desarticulação entre o ensino e a prática, entre o que o estudante aprende na academia e o que é aplicado na prática, bem como o que lhe é cobrado pelos enfermeiros das unidades, têm gerado manifestações de insatisfação docente $\mathrm{e}^{(3)} \mathrm{e}$, possivelmente, SM

Vivências de SM em estudantes também foram identificadas, em outro estudo, ao perceberem diferenças entre os princípios que aprenderam durante sua formação acadêmica e, posteriormente, quando desenvolvem sua atuação clínica(10)

Comportamentos de indiferença e, até, de hostilidade dos profissionais da equipe de enfermagem, nos campos de estágio, ao não receberem o estudante de maneira respeitosa e acolhedora, dificultando o desenvolvimento do processo ensino-aprendizagem e a formação de um profissional comprometido com as ações de cuidado, têm sido percebidas com insatisfação e sofrimento pelos docentes. Assim, faz-se necessária uma reflexão e crítica constante acerca das atitudes assumidas, no intuito de identificar bons e maus exemplos, para que modelos de profissionais, realmente comprometidos com sua prática, possam ser seguidos ${ }^{(4)}$.

Estudo referente às situações reconhecidas como de negligência no cuidado ao paciente revelou a frustração dos docentes por sentirem-se como "convidados", tendo suas ações limitadas, frente à realidade vivenciada pelos pacientes em unidades psiquiátricas, em que havia pouca ênfase e interação com o paciente, com predomínio de terapia medicamentosa e retenção de informações. Relatam, ainda, inconformidade com tal situação. Entretanto, com medo de represálias, como a possibilidade de perderem o campo de estágio para novos alunos, abstêm-se de impulsionar mudanças em tal contexto(19). Os docentes de enfermagem, assim, vêem-se continuamente desafiados na defesa dos padrões da profissão, bem como na manutenção de suas obrigações morais ${ }^{(15)}$.

Essas situações, quando vivenciadas, são potencialmente geradoras de repercussões negativas à ação docente e ao profissional em formação, pois ao mesmo tempo em que o docente se percebe como um modelo ao estudante, não intervém suficientemente, em tais situações ${ }^{(20)}$. Essa aparente impotência repercute em sofrimento docente, possivelmente em SM, pois, de um lado, está seu compromisso com a formação do estudante e, de outro, a constatação de que os espaços de ensino oferecidos não se configuram como 
apropriados ao contexto de formação.

É fundamental que novos estudos sejam realizados sobre - SM na docência de cursos técnicos em enfermagem, no sentido de problematizar e desnaturalizar práticas vivenciadas, cotidianamente. Faz-se necessário construir estratégias de enfrentamento que contribuam com a prática docente, o processo ensino-aprendizagem e a formação de técnicos de enfermagem comprometidos com a profissão e com o cuidado do outro.

\section{CONCLUSÃO}

Constatou-se que situações de conflitos e dilemas morais geradoras de SM estão presentes na prática dos docentes dos dois cursos técnicos em enfermagem. Manifestações de des(cuidado) com o paciente, seja por comportamentos inadequados do estudante em formação, que não coincidem com a assistência de qualidade almejada, seja pela dinâmica organizacional dos ambientes de estágio, associadas à carência de recursos materiais, bem como à atuação descomprometida dos trabalhadores de enfermagem, são potenciais catalizadores de SM nos docentes.

Entretanto, tais vivências dos docentes têm se configurado predominantemente como fontes de insatisfação e sofrimento no trabalho, sem a suficiente percepção da sua dimensão moral. É possível que se os docentes problematizassem esse cotidiano, procurando desnaturalizálo, preferentemente com seus pares, poderiam avançar para o reconhecimento da dimensão moral presente nesse sofrimento, entendendo-o como SM, fortalecendo-se para o enfrentamento dos problemas e dilemas morais vivenciados na prática educacional.

\section{REFERÊNCIAS}

1. Góes FSN, Côrrea AK, Camargo RAA, Hara CYN. Necessidades de aprendizagem de alunos da Educação Profissional de Nivel Técnico em Enfermagem. RevBrasEnferm. 2015; 68(1): 20-5.

2. Ferreira EM, Fernandes MF, Prado C, Baptista PCP, Freitas GF, Bonini BB. Prazer e sofrimento no processo de trabalho do enfermeiro docente. RevEscEnferm USP. 2009; 43(2): 1292-6. [Citado em 2015 mar ll]. Disponivel em: http://www.scielo.br/pdf/reeusp/v43nspe2/a25v43s2.pdf

3. Tavares PEN, Santos SAM, Comassetto I, Santos RM. Santana VVRS. A vivência do ser enfermeiro e preceptor em um hospital escola: olhar fenomenológico. Rev RENE. 2011; 2(4): 798-807.

4. Sebold LF, Carraro TE. Modos de ser enfermeiro-professor-no-ensinodo-cuidado de enfermagem: um olhar heideggeriano. RevBrasEnferm. 2013:66(4): 550-6.

5. Barlem ELD, Lunardi VL, Lunardi GL, Dalmolin GL, Tomaschewski JG. Vivência do sofrimento moral na enfermagem: percepção da enfermeira. RevEscEnferm USP. 2012; 46(3): 681-8.

6. Barlem ELD, Lunardi VL, Lunardi GL, Barlem-Tomaschewski JG, Silveira RS, Dalmolin GL. Sofrimento moral em trabalhadores da enfermagem. Rev Latino-Am Enfermagem. 2013; 21, spe: 79-87.

7. Dalmolin GL, Lunardi VL, Lunardi GL, BarlemELD, Silveira RS. Enfermeiros, técnicos ou auxiliares de enfermagem: quem vivencia maior sofrimento moral? Rev Esc Enferm USP. 2014; 48(3): 521-9.

8. Jameton A. Nursing Practice: The Ethical Issues. Prentice-Hall. EnglewoodClifss, NJ. 1984

9. Corley MC. Nurse moral distress: a proposed theory and research agenda. Nursing Ethics. 2002; 9(6): 636-50.

10.Sasso L, Bagnasco A, Bianchi M, Bressan V, Carnevale F. Moral distress in undergraduate nursing students: A systematic review. NursingEthics. 2015; 1-12. doi:10.1177/0969733015574926

11. Moraes R, Galiazzi MC. Análise textual discursiva. 2. ed. rev. Ijuí: Editora Unijuí, 2011.
12. Lunardi VL, Barlem ELD, Bulhosa MS, Santos SSC, Lunardi Filho WD Silveira, RS et al. Sofrimento moral e a dimensão ética no trabalho da enfermagem. RevBrasEnferm. 2009;62(4): 599-603.

13. Caregnato RCA, Martini RMF, Mutti RMV. Questão ético-moral na formação dos enfermeiros e médicos: efeitos de sentidos nos discursos docentes. Texto Contexto Enferm. 2009: 18(4): 713-21. [Citado em 2015 mar 15]. Disponivel em: http://www.scielo.br/scielo.php?script=sci_ arttextEpid=S0104-07072009000400013

14. Ribeiro KRB, Barros WCTS, Oliveira LPBA, Melo CR, Ramos FRS, Pires DEP. Reflexão sobre o sofrimento moral no trabalho do enfermeiro docente. Rev Enferm UFPE online. 2014: 8(3):765-70.

15. Pratt M. Martin L., Mohide A, Black M. A Descriptive Analysis of the Impact of Moral Distress on the Evaluation of Unsatisfactory Nursing Students. NursingForum. 2013; 48(4) 231-39.doi: 10.1111/nuf.12036.

16. Tomaschewski-Barlem JG, Lunardi VL, Ramos AM, Silveira RS, Barlem ELD, Ernandes CM. Manifestações da sindrome de burnout entre estudantes de graduação em enfermagem. Texto Contexto - Enferm. [Internet]. 2013: 22(3):754-62. [cited 2016 Jan 25]Disponivel em: http://www.scielo.br/ scielo.php?script=sci_arttext\&pid=S0104-07072013000300023\&lng=en.

17. Backes VMS, Moyá JLM, Prado ML. Processo de construção do conhecimento pedagógico do docente universitário de enfermagem. Rev Latino Am Enfermagem. 2011; 19(2):8 telas.

18. Ferreira Junior MA. Os reflexos da formação inicial na atuação dos professores enfermeiros. RevBrasEnferm. 2008; 6l(6). [Citado em 2015 mar 15] Disponivel em http://www scielo.br/scielo.php?script=sci arttextEpid=S0034-71672008000600012

19. Wojtowicz B, Hagen B. A guest in the house: nursing instructors experiences of the moral distress felt by students during inpatient psychiatric clinical rotations. Int J Nurse EducScholarsh. 2014: 23: 11:20130086.doi: 10.1515/ijnes-2013-0086.

20. Yoes T. Addressing Moral Distress: Challenge and Strategies for Nursing Faculty. Oklahoma Nurse. 2012: 57(2):14. 